九州大学学術情報リポジトリ

Kyushu University Institutional Repository

\title{
Farm Size and Productive Efficiency: Lessons from Smallholder Farms in Embu District, Kenya
}

Oduol, Judith Beatrice Auma

Graduate School of Bioresource and Bioenvironmental Sciences, Kyushu University

Hotta, Kazuhiko

Faculty of Agriculture, Kyushu University

Shinkai, Shoji

Faculty of Agriculture, Kyushu University

Tsuj i, Masao

Tokyo University of Agriculture

https://doi.org/10.5109/9269

出版情報: 九州大学大学院農学研究院紀要. 51 (2)，pp.449-458，2006-10-27. Faculty of Agriculture, Kyushu University

バージョン :

権利関係 : 


\title{
Farm Size and Productive Efficiency: Lessons from Smallholder Farms in Embu District, Kenya
}

\author{
Judith Beatrice Auma ODUOL ${ }^{1 *}$, Kazuhiko HOTTA ${ }^{2}$, \\ Shoji SHINKAI ${ }^{2}$ and Masao TSUJI ${ }^{3}$
}

\author{
Laboratory of Farm Management, Division of International Agricultural Resource Economics \\ and Business Administration, Department of Agricultural and Resource Economics, \\ Faculty of Agriculture, Kyushu University, Fukuoka 812-8581, Japan \\ (Received June 28, 2006 and accepted July 24, 2006)
}

\begin{abstract}
This paper examines the effect of farm size on the productive efficiency of smallholder farms in a landscarce Embu district of Kenya. In particular, the study seeks to establish the relationship between farm size and three components of productive efficiency, namely technical, scale and allocative efficiency. We use data envelopment analysis (DEA) to generate input oriented measures of productive efficiency from a 2004 cross-sectional survey data collected over 120 smallholder farms.

The results suggest that gains from improving technical efficiency exist in all farm categories, although they appear to be much higher on large and on medium farms than on small farms. While small farms tend to use land more intensively in an attempt to alleviate land constraints, the study suggests that the relatively higher level of technical efficiency observed on small farms is largely attributable to the adoption of traditional land saving techniques rather than the use of modern land saving technologies. On the other hand, scale inefficiency is found to account for a larger share of technical inefficiency on small farms than on medium and on large farms, suggesting that increasing the scale of operation is necessary if the households have to improve technical efficiency. Likewise, small farms are found to be less allocatively efficient than medium and large farms. Nevertheless, gains from improving allocative efficiency exist in more than $90 \%$ of the sample households. Accordingly, measures aimed at reducing labour congestion on the farms, relaxing liquidity constraints, and improving the functioning of land rental markets can significantly improve productive efficiency.
\end{abstract}

\section{INTRODUCTION}

In many parts of sub-Saharan Africa, agriculture remains at the core of rural livelihoods and has a major influence on livelihood outcomes. Land is one of the most crucial inputs in the agricultural production process of majority of rural households. Thus, factors that reduce the rural households' access to land significantly affect agricultural productivity, thereby compromising the households livelihood. Available evidence shows that shortage of arable land is one of the main challenges facing many farm households in sub-sarahan Africa (Reardon et al., 1996). The problem of scarcity of arable land in many parts of the continent has been exacerbated by high population growth rate and the accompanying increase in demand for food (Binswanger and Pingali, 1988). In addition, because of lack of alternative investment and employment opportunities in the non-farm sector, land has become a major source of investment as well as employment for the burgeoning rural population, with a resultant decline in the average land holding size. In Kenya, for example, only 16\% of the land is designated as high and medium potential agricultural land on which more than 70 to $80 \%$ of the

${ }^{1}$ Laboratory of Farm Management, Division of International Agricultural Resource Economics and Business Administration, Department of Agricultural and Resource Economics, Graduate School of Bioresource and Bioenvironmental Sciences, Kyushu University

${ }^{2}$ Faculty of Agriculture, Kyushu University

3 Tokyo University of Agriculture

* Corresponding author (E-mail: juduol@yahoo.com) population is concentrated (Lele and Stone, 1989). Consequently, population pressure coupled with escalating unemployment in the country has led to the sub-division of farmland and the decline in the average holding size in the smallholder sub-sector. Jayne et al. (2003) report an average per capita farm holding size of approximately 0.58 hectare for the lowest land quartile in the smallholder sector in Kenya.

To mitigate land constraints, smallholder farmers have adopted a number of strategies that aim at optimizing the use of land resources in accordance with the theory of induced innovation suggested by Boserup (1965) and Hayami and Ruttan (1985). First, the long bush fallows that were previously salient features of agriculture on the continent have yielded to shorter grass fallows and continuous cultivation. Second, practices such as monoculture and single cropping have given way to intercropping and multiple cropping. Third, as land becomes expensive relative to productivity enhancing inputs, such as fertilizers and high yielding crop varieties, smallholder farmers have attempted to substitute productivity enhancing inputs for land. Nevertheless, there is growing concern whether these intensification pathways have translated into a desired level of economic efficiency on smallholder farms. Moreover, in recent years, the productivity and efficiency of smallholder farms in the high and medium agricultural potential regions of Kenya have become under scrutiny as land constraints increase and the smallholder farmers are forced to farm on tiny plots. This is because the prevailing farm size has most often been contemplated as suboptimal and seen as the reason for inefficient use of 
resources on smallholder farms. In fact, many farms are thought to be too small to employ fully the available family labour, which may result in low productive efficiency on smallholder farms despite an attempt to substitute modern inputs for land.

The purpose of this paper is to examine the effect of farm size on productive efficiency of smallholder farms in Embu district. In particular, the study seeks to establish the relationship between farm size and technical, scale, and allocative efficiency. The use of data envelopment analysis (DEA) provides an opportunity to decompose cost efficiency into allocative and technical efficiency (and the latter into scale and pure technical efficiency). The results should shed light on the relative importance of the different types of inefficiency and their impact on productive efficiency of the smallholder farmers under analysis.

The rest of the paper is organised as follows: Section two discusses issues pertinent to the non-parametric methodology as well as the data used in this paper. Empirical findings are presented in section three and discussed in section four while section five presents summary and conclusions.

\section{METHODOLOGY}

\section{Measurement of productive efficiency}

Measurement of productive efficiency draws on the seminal work of Farrell (1957) who suggested that the efficiency of a firm consists of two components: technical and allocative efficiency. Technical efficiency is a measure of the ability of a firm to obtain maximum output from a bundle of inputs given the best available technology. Allocative efficiency, on the other hand, reflects the ability of a firm to use factors in proportions that maximise producer profits or minimize costs, given the prevailing input prices. Two approaches are generally used to derive estimates of efficiency: parametric and non-parametric methods ${ }^{1}$. The parametric approach involves specifying and estimating a parametric production function, which can be cost or profit function. On the other hand, the non-parametric approach is a measure directed to frontiers rather than central tendencies. It uses mathematical programming techniques and models to evaluate the performance of "best practice farmers" in terms of multiple inputs used and multiple outputs produced. The two approaches have their strengths and weaknesses. While the parametric method provides a basis for hypothesis testing, it is more prone to misspecification error (Coelli et al., 1998). By contrast, the non-parametric method does not require a priori information of the functional relationship between the inputs and output, but the efficiency estimates can be confounded with effects of random noise, measurement error, and exogenous factors beyond the manager's control (Fare et al., 1985; Lovell, 1993; Ray, 2004). The choice between the two approaches depends on the

\footnotetext{
See Coelli et al., 1998 for an overview of the two approaches.
}

type and quality of data available, and the underlying reasons for estimating productive efficiency. With good quality data, non-parametric measures can be adept at discovering relationships between inputs and output that are hidden to other methodologies (Cooper et al., 2004). We used the non-parametric method to generate estimates of productive efficiency.

Economic literature on productive efficiency identifies two non-parametric methods for obtaining efficiency estimates, namely data envelopment analysis (DEA) and total factor productivity indices (TFP). Unlike the latter method, the former can be applied to data on a sample of farms, thereby providing relative measures of efficiency among farms. The latter method assumes that the decision-making units (DMUs) under investigation are technically efficient, and is generally applied to time series data to estimate changes in technical efficiency (Coelli et al., 1998). Considering the nature of our data and our hypothesis that land and capital constraints engender heterogeneity in terms of access to technology among the sample households, DEA method has been used in this study. Although DEA was initially developed for use in the public sector, where prices were unreliable or missing (Lovell, 1993), it has been extensively used as a tool for measuring efficiency in a number of fields including agriculture (see Chavas et al., 2005; Rios and Shively, 2005; Helfand and Levine, 2004).

Estimation of technical and scale efficiency

Technical efficiency scores can be obtained by running a constant returns to scale (CRS) DEA model (Charnes et al., 1978), or a variable returns to scale (VRS) DEA model. The application of CRS DEA model is generally suited to DMUs operating at optimal scale (Coelli et al., 1998). Nonetheless, factors such as financial constraints, imperfect competition among other things can cause firms not to operate at optimal scale. Under this circumstance, the use of CRS will result in efficiency measures confounded with scale efficiency (Coelli et al., 1998). The use of VRS specification, suggested by Banker et al. (1984), to account for variable returns to scale permits the calculation of efficiency scores free from scale efficiency effects. Because majority of our sample households face land and financial constraints, we estimated technical efficiency scores using the two approaches and then decomposed technical efficiency into scale and pure technical efficiency. We decomposed technical efficiency scores into the two components because our interest was to determine the extent to which the inefficiency of being 'too small' reduces the gains that the households can realise from improved farming techniques.

Two alternative approaches, input-oriented and output-oriented, are available in DEA to estimate the efficient frontier. Input-oriented measures attempt to measure the extent to which input quantities can be proportionally reduced without altering the output quantities produced, whereas output-oriented measures estimate the amount by which output quantities can be proportionally expanded without altering the quantities 
of inputs used. The choice between the two approaches depends on which quantities (inputs or outputs) a manager has control over. In this paper, an input orientation was chosen because we believe that the farm households have a greater control over input quantities. In order to obtain VRS technical efficiency scores, we solve the following linear programming problem²:

$$
\begin{aligned}
& \text { (1) } \begin{array}{c}
\theta *=\min \theta \\
\text { subject to }
\end{array} \\
& \sum_{j=1}^{n} \lambda_{j} x_{i j} \leq \theta x_{i 0} \\
& \sum_{j=1}^{n} \lambda_{j} y_{r j} \geq y_{r o} \\
& \sum_{j=1}^{n} \lambda j=1
\end{aligned}
$$

$$
\lambda j \geq 0
$$

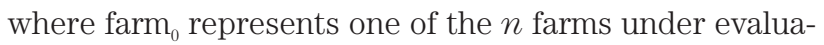
tion, and $\mathrm{x}_{\mathrm{i} 0}$ and $\mathrm{y}_{\mathrm{ro}}$ are the $i$ th input and $r$ th output for farm $_{0}$, respectively. $\lambda_{j}$ is a non-negative scalar assigned to the $j$ th farm in forming convex combination of input vectors. $\theta *$ represents the input-oriented efficiency score of farm $_{0}$. If $\theta *=1$, then the current input levels cannot be reduced (proportionally), indicating that farm $_{0}$ is on the frontier (technically efficient). Otherwise, if $\theta *<1$, then farm $_{0}$ is dominated by the frontier, and $1-\theta *$ indicates the level of technical inefficiency.

Scale efficiency (SE) can be obtained residually from VRS and CRS technical efficiency scores as follows:

$$
\mathrm{SE}=\mathrm{TE}_{\mathrm{CRS}} / \mathrm{TE}_{\mathrm{VRS}}
$$

where $\mathrm{TE}_{\mathrm{CRS}}$ and $\mathrm{TE}_{\mathrm{VRS}}$ are technical efficiencies under constant and variable returns to scale, respectively. Note that scale efficiency measures, like those of technical efficiency, are bounded by zero and one, where a value equal to one indicates that such a farm is of the appropriate size so that no reorganisation of its size will reduce costs or improve output.

Estimation of allocative efficiency

In order to obtain allocative efficiency scores, one can estimate cost or profit or revenue efficiency, depending on the objective of the DMUs under evaluation, and then decompose the estimated scores into technical and allocative efficiency. We estimated cost efficiency for the sample households based on the premise that constraints on inputs (land and capital) compel households to strive to minimise costs on inputs

\footnotetext{
${ }^{2}$ CRS linear programming problem is the same as the VRS one except that the CRS problem does not have the convexity constraint$$
\sum_{j=1}^{n} \lambda j=1
$$

while maintaining output at the same level. Cost efficient farms can be identified by solving the following linear programming problem, under the assumption of variable returns to scale:

$$
\begin{aligned}
& \min \sum_{j=1}^{m} w_{i} x_{i o}{ }^{*} \\
& \text { Subject to } \\
& \sum_{j=1}^{n} \lambda_{j} x_{i j} \leq x_{i o} \\
& \sum_{j=1}^{n} \Lambda_{j} y_{r j} \geq y_{r o} \\
& \sum_{j=1}^{n} \lambda j=1
\end{aligned}
$$

$$
\lambda j \geq 0
$$

Where $w_{\mathrm{i}}$ denotes the $i$ th input price for farm $\mathrm{and}_{0}{ }_{i}{ }^{*}$ represents the $i$ th input that minimises cost for the i-th farm at the prevailing input prices $\mathrm{w}_{\mathrm{i}}$ and the output levels $\mathrm{y}_{\mathrm{r}}$. The total cost efficiency (CE) or economic efficiency of the $\mathrm{i}-\mathrm{th}$ farm is calculated as the ratio between the optimal cost $\left(\mathrm{w}_{\mathrm{i}} \mathrm{x}_{\mathrm{i}}^{*}\right)$ and the observed cost on the $j$ th farm being evaluated for efficiency $\left(\mathrm{w}_{\mathrm{i}} \mathrm{x}_{\mathrm{io}}\right)$. Likewise, this measure attains a value of unity if the producer is cost efficient and a value less than unity indicates the degree of cost inefficiency. A measure of input-oriented allocative efficiency is then obtained residually as the ratio of the measure of cost efficiency (CE) to the VRS input-oriented technical efficiency (Fried et al., 1993). Thus, a producer has to be both technically and allocatively efficient in order to be cost efficient. Note that both $\mathrm{CE}$ and TE scores were generated by DEA Excel solver software developed by Zhu (2002). In estimating cost efficiency scores, we have assumed that the farm households face the same prices for inputs. While this assumption may result in fewer farms on the frontier, it is justified because the efficiency scores estimated reflect the farm households' relative degree of efficiency rather than the effect of different prices confronting them. Cost efficiency estimates obtained following the described procedure usually have three components: the technical component, a slack component, and an allocative component (Lovell, 1993). Assigning the slack component to allocative efficiency is usually accounted for by the fact that slacks reflect inappropriate input combination (Ferrier and Lovell, 1990). For this reason, we have discussed slack and surplus variables under allocative efficiency.

\section{Data}

The data used in this study are derived from a cross sectional household survey conducted between July and August 2004. For empirical analysis, we focused on three divisions of Embu district, namely Kyeni, Runyenjes, and Nembure, which are situated in the upper midland agro-ecological zone 2 (the main coffee 
zone). Concentrating on one region is expected to minimize the wide variation in farming practices observed at the national level. In particular, focusing on one region reduces the price variation, an important consideration given our assumption that all farms face the same prices for inputs and outputs. The sample households were selected using a stratified random sampling method, in which the households were stratified based on whether they were cultivating coffee and maize, which are the main cash crop and food crop in the region, respectively.

The data were collected through face-to-face interviewing of 120 farm households using a structured questionnaire. After data entry and cleaning, nine farm households were excluded from the analysis because of inconsistency in the data they provided. In addition, some of the excluded respondents had abandoned coffee enterprise, and hence did not report any costs or output in the enterprise. As a result, the findings reported here are based on the data obtained from 111 farm households. The purpose of the survey was to obtain information on costs and returns in crop enterprises undertaken on the farm in short rains 2003. Although the sample households cultivated several crops, the data were collected on only five crop enterprises, namely maize, coffee, beans, Irish potato and vegetables, which were cultivated by at least $30 \%$ of the respondents. The decision to collect data on a few crops rather than on all the crop enterprises was aimed at making the data tractable and the results comparable across the farm households. Besides, returns from non-crop enterprises, such as livestock and non-farm activities, were not added to crop output, because our objective was to assess how resource use efficiency in crop enterprises varies with farm size (land area). Consequently, the results reported here should be interpreted in relation to crop enterprises, because farmers who show inefficient use of resources in crop enterprises could still be using their labour and capital efficiently in non-crop enterprises.

Our study models farm households as multi-input and single-output DMUs, which attempt to minimize costs for given inputs and outputs. The farm households' productive activities are disaggregated into three inputs used to produce one output. The total output in this case is the value of crop production, obtained by aggregating output from maize, coffee, beans, potato, and vegetable enterprises using their respective prevailing market prices. The three inputs ${ }^{3}$ include land (ha), labour (workdays) and variable inputs ${ }^{4}$ (cost of pesticides, fertilizer, seeds, and organic manure).

The analysis of cost efficiency, from which allocative

\footnotetext{
Expenses on capital goods (machinery) are not included in the households' input bundle because agricultural mechanisation is virtually absent in the study region. As a result, farming in the region is labour intensive and farmers rely on simple hand tools such as machetes and hoes, so that the share of capital expenses in total cost is almost negligible.

${ }^{4}$ Since variable inputs enter the model as values rather than as physical quantities, the estimated technical efficiency scores will be conflated with allocative efficiency.
}

efficiency scores are derived, requires input and output prices. Small variations in output prices were observed across the divisions except for some crops such as coffee whose prices varied with the buying centre. Since variations in prices of output were unlikely to reflect differences in resource scarcity across the households, input and output median prices were chosen as measures of resource scarcity for the households. Median prices as opposed to average prices were used because median prices are less sensitive to outliers. Because majority of the households used mainly family labour and owned land, the implicit compensation for unpaid family labour and owned land (i.e. the wage and rent accruing to the two resources) was estimated by the prevailing wage rate and land rent in the study region. We believe that the going wage rate closely approximates the opportunity cost of family labour because that is what the respondents would receive if they were to be hired to work in a neighbouring farm. Likewise, the prevailing land rent reflects what the households would receive if they rented out their land.

In order to assess the extent to which productive efficiency varies with farm size, the sample households were classified into three categories according to the total size of landholding under maize, coffee, beans, potato, and vegetables. The analysis was conducted by pooling together all the households from the three farm categories and then the computed efficiency measures were compared across the three categories herein referred to as "small", "medium", and "large" farms ${ }^{5}$. The small, medium and large farms are defined as farms with total land size less than 0.5 ha, between 0.5 ha and one ha, and greater than 1 hectare planted to the five crops, respectively.

\section{RESULTS}

\section{Characteristics of the sample households}

Levels of use of inputs on the surveyed farms and the value of output ${ }^{6}$ produced are summarised in Table 1. On average, the households operate 1.14 hectares of land, of which only $9 \%$ is rented in. Although majority of the households in the small farm category face severe land constraints, the proportion of rented land accounts for only $14 \%$ of the total operation holding in this category. Virtually all the land operated by the households is under arable farming (81\%), suggesting that the intensity of land use is generally high in the study

\footnotetext{
5 The naming of the categories should not be confused with economic size since all the sample households are smallholder farmers. This classification is only adopted in order to illustrate how resource use efficiency varies with land scarcity. Official statistics define smallholder farms as farms with holdings less than 12 hectares, although the minimum acreage varies from one region to another, depending on the degree of land scarcity and agricultural potential of the region (GOK, 2003).

${ }^{6}$ 6Averages for labour and variable inputs given in Table 1 are expressed in per hectare basis for comparison. Nevertheless, the two inputs were used in the DEA model in per-farm terms.
} 
Table 1. Levels of use of inputs and value of crop output

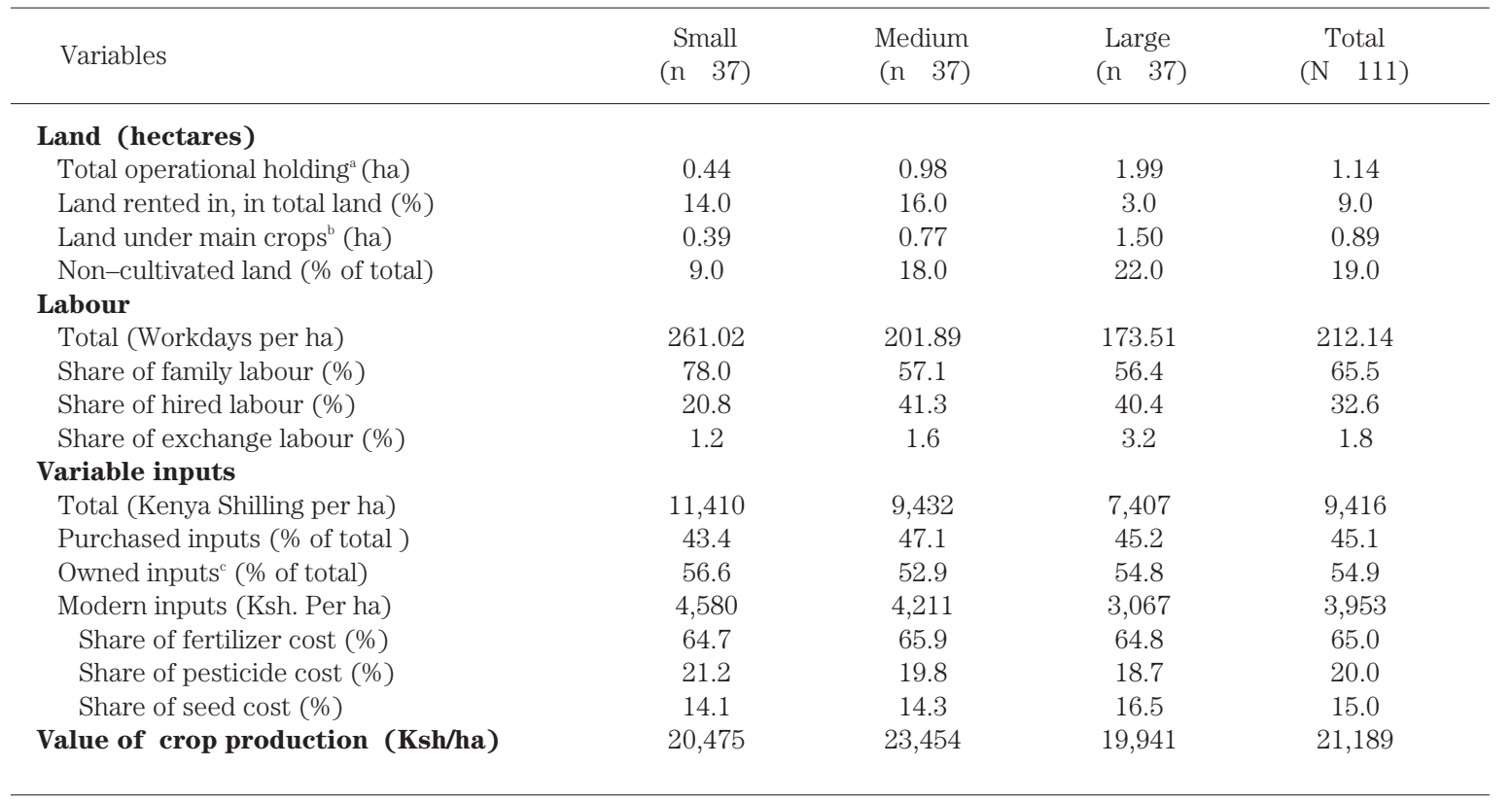

a Total operational holding $=$ owned land + land rented in - land rented out

b Total land planted with maize, beans, potato, coffee, and vegetables

Includes owned manure and local seed or retained improved seed

Source: Survey, 2004

region, especially on small farms.

Farming in the study area is labour intensive, and farmers do not use machinery or draught power. The sample households rely on three sources of human labour, namely family, hired and exchange labour. Of the three sources, family labour is the main source of agricultural labour, accounting for $65 \%$ of the labour used in the five crop enterprises. Moreover, family labour contributes more than 50\% of the labour requirements in the three farm categories, and the need to hire labour arises as farm size increases. Labour-land ratio is higher on small farms than on medium and on large farms.

According to the data, total expenditure on variable inputs per hectare is 1.2 and 1.5 times higher on small farms than on medium and on large farms, respectively. Nevertheless, the opportunity cost of owned inputs, such as seeds and manure, accounts for over 50\% of expenses on variable inputs used in the three farm categories. Total expenses on modern inputs are 1.5 times higher on small farms than on large farms, but account for only $40 \%$ of the total expenses on variable inputs used on small farms, and $45 \%$ and $41 \%$ on medium and on large farms, respectively. Although the levels of use of labour and variable inputs are higher on small farms than on medium and on large farms, the value of crop output on small farms is only 3\% (Kshs. 534 per ha) higher than that on large farms and $13 \%$ (Kshs. 2,979 per ha) lower than output on medium farms.

\section{Efficiency measures}

\section{Technical efficiency}

Table 2 presents mean efficiency estimates for the three farm categories. The results show an average overall technical efficiency of 54\%, implying that the households would have to reduce the level of inputs by $46 \%$ if they were operating at the frontier. The overall technical inefficiency ranges from 55\% on small farms to $41 \%$ on large farms, suggesting that large farms are more technically efficient than small farms. Nevertheless, the decomposition of technical efficiency into pure technical efficiency and scale efficiency reveals that small farms are more technically efficient than large farms. Thus, the high level of technical effi-

Table 2. Estimated mean efficiency measures and proportion of efficient farms

\begin{tabular}{|c|c|c|c|c|c|c|c|c|}
\hline \multirow{2}{*}{$\begin{array}{l}\text { Efficiency } \\
\text { measures }\end{array}$} & \multicolumn{2}{|c|}{ Small } & \multicolumn{2}{|c|}{ Medium } & \multicolumn{2}{|c|}{ Large } & \multicolumn{2}{|c|}{ Total } \\
\hline & Mean & $\%$ & Mean & $\%$ & Mean & $\%$ & Mean & $\%$ \\
\hline Overall technical efficiency (TE) & 0.45 & 0.0 & 0.58 & 2.7 & 0.59 & 4.5 & 0.54 & 7.2 \\
\hline Pure technical efficiency (PTE) & 0.78 & 7.2 & 0.68 & 5.4 & 0.65 & 7.2 & 0.71 & 19.8 \\
\hline Scale efficiency (SE) & 0.59 & 0.0 & 0.85 & 2.7 & 0.90 & 8.1 & 0.79 & 10.8 \\
\hline Allocative efficiency (AE) & 0.68 & 1.8 & 0.79 & 0.9 & 0.85 & 4.5 & 0.77 & 7.2 \\
\hline
\end{tabular}

\footnotetext{
${ }^{\dagger}$ Source: Survey, 2004
} 
Table 3. Bonferroni multiple comparison tests for the differences in mean efficiency estimates among farm categories

\begin{tabular}{|c|c|c|c|c|c|c|}
\hline \multirow{2}{*}{$\begin{array}{l}\text { Efficiency } \\
\text { measures }\end{array}$} & \multicolumn{2}{|c|}{ Small versus Medium } & \multicolumn{2}{|c|}{ Small versus Large } & \multicolumn{2}{|c|}{ Medium versus large } \\
\hline & $\begin{array}{c}\text { Mean } \\
\text { difference }\end{array}$ & Sig. ${ }^{a}$ & $\begin{array}{c}\text { Mean } \\
\text { difference }\end{array}$ & Sig. & $\begin{array}{c}\text { Mean } \\
\text { difference }\end{array}$ & Sig. \\
\hline $\mathrm{TE}$ & -0.123 & 0.101 & -0.130 & 0.074 & -0.007 & 1.000 \\
\hline PTE & 0.102 & 0.127 & $0.133^{*}$ & 0.025 & 0.003 & 1.000 \\
\hline $\mathrm{SE}$ & $-0.258 * *$ & 0.000 & $-0.304^{* *}$ & 0.000 & -0.046 & 0.648 \\
\hline $\mathrm{AE}$ & $-0.102^{*}$ & 0.032 & $-0.153 * *$ & 0.000 & -0.051 & 0.584 \\
\hline
\end{tabular}

Note: $* *$ and $*$ denote significance at 0.01 and 0.05 respectively

a Tukey corrected significance value

${ }^{\dagger}$ Source: Survey, 2004

ciency observed on large farms, under constant returns to scale assumption, is largely due to scale efficiency. On average, pure technical efficiency scores show a lower level of inefficiency of about $29 \%$, although the degree of inefficiency ranges from $22 \%$ on small farms to $35 \%$ on large farms.

Only $7 \%$ of the sample households are technically efficient under constant returns to scale, and none of the households in the small farm category is technically efficient, suggesting that the households could be facing constraints in accessing modern technologies. Likewise, only about $20 \%$ of the households are technically efficient under variable returns to scale. The Bonferroni multiple comparison test for significant differences in mean technical efficiency among the three farm categories, summarised in Table 3, confirms that mean pure technical efficiency is significantly higher on small farms than on large farms. Accordingly, the mean pure technical efficiency results suggest that gains from improving technical efficiency exist in all the farm categories, although they appear to be much higher on large and medium farms than on small farms.

\section{Scale efficiency}

The decomposition of technical efficiency shows that, on average, the households are more scale efficient than they are technically efficient. Mean scale efficiency is 0.79 , but ranges from a low of 0.59 on small farms to a high of 0.90 on large farms (Table 2). Besides, scale inefficiency accounts for nearly $50 \%$ of technical inefficiency at the farm level, and over 70\%, 36\% and $24 \%$ of technical inefficiency on small, medium, and large farms, respectively. The results in Table 3 indicate that mean scale efficiency scores are statistically significantly higher on medium and on large farms than on small farms. Nevertheless, only $11 \%$ of the households are operating at optimal scale, while majority are scale inefficient (either operating at increasing or decreasing returns to scale).

In order to discern the nature of scale inefficiency, the analysis was further disaggregated into those households that exhibit increasing returns to scale and are 'too small' to utilize the available resources efficiently and those that exhibit decreasing returns to scale and are 'too large'. On average, the inefficiency of being 'too small' is found to be more severe among the sample households than the inefficiency of being 'too large'.
Over $80 \%$ of the households exhibit increasing returns to scale, with the proportion varying from $100 \%$ on small farms to $91 \%$ and $60 \%$ on medium and on large farms, respectively. Only 9\% of the households exhibit decreasing returns to scale and all of them belong to the large farm category. Thus, our findings suggest that the sample households, particularly those in the small farm category, can reduce costs further by increasing their scale of operation or reducing input congestion by reallocating some of the over utilized resources to other enterprises where they can be utilised fully.

\section{Allocative efficiency}

Table 2 shows an average allocative efficiency of $77 \%$ for the sample households, suggesting that the inefficiency due to inappropriate input mix accounts for $23 \%$ of the loss in the households' income. The degree of allocative inefficiency ranges from $32 \%$ on small farms to $15 \%$ on large farms. Nonetheless, there are fewer allocatively efficient households than there are technically efficient households, implying that allocative inefficiency is the primary source of cost inefficiency in majority of the households. While about $20 \%$ of the households are technically efficient, only $7 \%$ are allocatively efficient. Thus, the presence of allocative inefficiency suggests both lack of cost minimising behaviour among the households and the possibility of reducing costs by reallocating the available resources to other enterprises where they can be utilised fully. The Bonferroni multiple comparison test for significant differences in the mean allocative efficiency between the three farm categories indicates that medium and large farms are statistically significantly more allocatively efficient than small farms.

Because inefficient use of a particular input may vary with farm size, we examined whether any distinct pattern exists across the three farm categories with respect to excessive use of land, labour, and variable inputs. This is achieved by analysing slack and surplus variables obtained from the analysis of pure technical efficiency. Whilst slacks represent another dimension of technical inefficiency, they provide an insight into the extent to which households misallocate inputs, and thus can be partly interpreted as allocative inefficiency. Table 4 gives a summary of slack and surplus variables as well as the proportion of households with zero slack and zero surplus variables for inputs and output, respec- 
Table 4. Analysis of slack and surplus variables

\begin{tabular}{lccc}
\hline $\begin{array}{l}\text { Variables by farm } \\
\text { category }\end{array}$ & Mean & $\begin{array}{c}\text { Total } \\
\text { slack/surplus as } \\
\text { a of total } \\
\text { input/output }\end{array}$ & $\begin{array}{c}\text { \% of farms } \\
\text { with zero } \\
\text { slack/surplus }\end{array}$ \\
\hline Small & & & \\
$\quad$ Land (ha) & 0.00 & 0.00 & 100 \\
$\quad$ Variable inputs (Ksh) & 684 & 9.19 & 64.9 \\
$\quad$ Labour (Workdays) & 6.72 & 3.68 & 73.0 \\
$\quad$ Output (Ksh.) & 54.65 & 1.49 & 94.6 \\
Medium & & & \\
$\quad$ Land (ha) & 0.01 & 0.89 & 91.9 \\
$\quad$ Variable inputs (Ksh) & 589 & 1.70 & 94.6 \\
$\quad$ Labour (Workdays) & 3.70 & 1.65 & 81.1 \\
$\quad$ Output (Ksh.) & 4.40 & 0.08 & 97.3 \\
Large & & & \\
$\quad$ Land (ha) & 0.11 & 5.24 & 75.7 \\
$\quad$ Variable inputs (Ksh) & 120 & 0.57 & 97.3 \\
$\quad$ Labour (Workdays) & 4.10 & 1.51 & 91.9 \\
$\quad$ Output (Ksh.) & 0.003 & 0.00 & 97.3 \\
$\quad$ Total & & & \\
$\quad$ Land (ha) & 0.04 & 2.05 & 89.2 \\
$\quad$ Variable inputs (Ksh) & 465 & 3.82 & 85.6 \\
$\quad$ Labour (Workdays) & 4.84 & 2.28 & 82.0 \\
$\quad$ Output (Ksh.) & 19.69 & 0.52 & 96.4 \\
\hline
\end{tabular}

Source: Survey, 2004

tively. Whereas slacks indicate the amount of excessive input use, surplus variables reveal the extent to which a household on the production frontier could further increase its output without using additional inputs.

The results suggest that there is misallocation of all the three inputs, although the degree of overuse varies with the type of input and farm category. The data show that $18 \%$ of the households have positive slacks for labour, whereas $14 \%$ and $11 \%$ of the households have positive slacks for variable inputs and land, respectively. Of the $18 \%$ with slack variables for labour, $50 \%$ are from the small farm category and the remaining 35\% and 15\% are from the medium and the large farm categories, respectively. Likewise, the results show that small farms tend to overuse variable inputs. Of the $14 \%$ of the households with positive slacks for variable inputs, $81 \%$ are from the small farm category while $13 \%$ and $6 \%$ are from the medium and the large farm categories, respectively. Conversely, misallocation of land varies positively with farm size, in which case the large farms form the largest proportion of households with slack variables for land (75\%) and none of the households in the small farm category has slacks for land. Overall, the data suggest that the households have a greater potential to reduce costs by reducing the amount of labour than by reducing the amount of land and variable inputs.

With regard to surplus variables, the data suggest that households with positive surplus have the potential, on average, to increase total output by about Ksh. 20 without consuming additional inputs. The loss due to underproduction accounts for less than $1 \%$ of the total output, indicating a very low potential for increasing output with the current levels of inputs. This potential declines with an increase in farm size, suggesting that under production is a major concern to farms with land sizes too small to utilize labour and variable inputs to their fullest.

\section{DISCUSSION}

\section{Technical efficiency}

The study finds evidence of a significantly higher mean pure technical efficiency on small farms than on large farms (Table 3). This can be attributed to the fact that small farms are land-constrained and thus tend to use land more intensively than large farms. In contrast, large farms tend to treat land as a relatively more abundant resource even though land is scarce in the region. For instance, the results show that $91 \%$ of the total holding on small farms was under arable farming, compared with $78 \%$ on large farms (Table 1). Because small farms have surplus family labour, they can exploit more land and hence bring a larger share of their land under cultivation, which results in higher output per unit of land than on large farms. Additionally, our findings show that small farms, when confronted by land constraints, resort to traditional land saving techniques such as intercropping, which do not require capital outlays. According to the survey results, the proportion of households practicing intercropping on small farms was $76 \%$, compared with $60 \%$ and $54 \%$ on medium and large farms, respectively.

Besides, the data in Table 1 show that small farms tend to use higher levels of productivity enhancing inputs than large farms, which could be reflective of their attempt to substitute productivity enhancing inputs for scarce and hence relatively expensive land. Nevertheless, expenses on modern inputs are only 1.5 times higher on small farms than on large farms, suggesting that the households could be facing constraints in accessing modern land saving techniques. It is therefore apparent that resource scarcity is only necessary but not sufficient condition for achieving higher technical efficiency. Accordingly, it is important to explore some of the underlying reasons for the low level of technical efficiency observed among the farm households.

Factors such as low cash availability can have a direct effect on the level of technical efficiency. Low cash availability may engender selective adoption and partial implementation of modern land saving techniques (innovations), thereby resulting in low levels of technical efficiency. An examination of the households' liquidity position indicates that, on average, cash expenses per hectare exceed cash receipts from crop enterprises by Ksh. 548, and that the gap between cash expenses and cash receipts (net cash income) widens further when non-cash revenue from coffee $^{7}$ is treated as such (Table 5). Thus, the results suggest that the households are not able to generate sufficient revenue to cover their cash expenses. In order for the house-

\footnotetext{
Gross revenue from coffee is considered as non-cash income for the households who had not yet received their dues at the time of the survey.
} 
Table 5. Gross cash receipts and cash expenses in crop enterprises

\begin{tabular}{lccc}
\hline \multirow{2}{*}{$\begin{array}{l}\text { Farm } \\
\text { category }\end{array}$} & $\begin{array}{c}\text { Gotal cash } \\
\text { receipts }^{\mathrm{a}}\end{array}$ & $\begin{array}{c}\text { Actual cash } \\
\text { receipts }^{\mathrm{b}}\end{array}$ & $\begin{array}{c}\text { Total cash } \\
\text { expenses } \\
\text { (Ksh/ha) }\end{array}$ \\
\cline { 2 - 3 } Small & $8,756(-1,853) *$ & $6,385(-4,224)$ & 10,609 \\
Medium & $13,029(-1,189)$ & $9,135(-5,083)$ & 14,218 \\
Large & $12,862(-1,398)$ & $9,726(-1,738)$ & 11,464 \\
Total & $11,549(-548)$ & $8,415(-3,682)$ & 12,097 \\
\hline
\end{tabular}

* Figures in parentheses are net cash income per ha

a Includes coffee dues owed to the farmer

b Total cash receipts less coffee dues owed to the farmer

+ Source: Survey, 2004

holds to have economic access to modern inputs, their cash receipts must exceed their cash expenses by a significant margin.

In the event that equity capital is not sufficient to finance farming activities, the households can resort to borrowing (debt capital). However, our results show that use of credit was extremely low (only 16\% of the households had access to credit), indicating that the households could be credit constrained. At least $11 \%$ of the households sought credit from the coffee cooperatives but did not qualify because of low output while $19 \%$ did not have access to credit following the collapse of the coffee cooperative in their village. Besides, nearly half of the sample households cited lack of credit as a constraint but did not seek for credit for fear of defaulting on the loan. Thus, these findings point to the conclusion that underdeveloped or poorly functioning credit market coupled with low capital accumulation may have a significant impact on the level of technical efficiency on smallholder farms.

\section{Scale efficiency}

With regard to scale efficiency, the finding that more than $80 \%$ of the households are operating under increasing returns to scale reinforces our presupposition that the farms operated by the households could be too small to absorb surplus family labour. On the other hand, the presence of decreasing returns scale on $27 \%$ of the large farms ( $9 \%$ of the households) can be attributed to lack of adequate capital and managerial ability to utilize the available land effectively. It is, however, apparent that majority of the households can significantly reduce costs and improve productive efficiency by reducing labour congestion on their farms in two ways: bringing additional land into cultivation or releasing surplus family labour to search for employment in non-farm sector. Nevertheless, the feasibility of the latter option depends on factors such as the probability of finding employment outside the farm, skills possessed by the surplus family labour and the gap between farm income and the expected wage in the non-farm sector. The low level of education of majority of the household members implies that most of them have limited chances of securing employment in the non-farm sector.
The finding that only an average of $15 \%$ of the households were employed in the non-farm sector on a full-time basis lends credence to our assertion that off-farm employment may not be a pragmatic solution to labour congestion on the smallholder farms.

Thus, expanding scale of operation by bringing additional land into cultivation (mainly through temporary acquisition or renting in) to utilize the surplus family labour appears to be the only feasible option. Yet it appears that majority of the households are hesitant to rent in additional land. Only 31\% of the households rented in land although 59\% owned less than 1 hectare of land. Of the $31 \%$ who rented in land, $44 \%, 41 \%$, and $15 \%$ were from the small, medium, and large farm categories, respectively. Moreover, the average size of land rented in accounted for only $9 \%$ of the total operational holding. This finding suggests that the households could be facing physical and economic barriers in accessing arable land. Physical barriers may be due to shortage of rental land and poorly functioning land rental markets while economic barriers may stem from lack of working capital due to low capital accumulation and lack of credit.

Because majority of the households rely on farming as their main occupation, it is highly likely that shortage of rental land could be one of the underlying reasons for the farmers' reluctance to increase their scale of operation. The results show that only $4 \%$ of the households rented out land, thus suggesting that land constraints cut across the three farm categories, and that the possibility of renting in land within the district may be limited.

Poorly functioning land rental market can be an impediment to temporary acquisition of additional land for the households who might be willing to expand their scale of production. Although our study may not have sufficient corroborative evidence on the nature of imperfections in the land rental market confronting the households, anecdotal evidence suggests that insecurity of tenure may be a major concern to the prospective tenants. Observations made on the sample households, who rented in or leased out land, point to the conclusion that lack of well-developed land rental markets could be significant in explaining why the households are reluctant to rent in or lease out land. According to the findings, land rental transactions were more common among relatives and friends than among outsiders (farmers from a different village). Such transactions, though may be justified on the grounds that they make up for information asymmetry, might result in rationing of land and hence lock out land-constrained households who may be willing to augment their land but are not related to the relatively land-abundant households. In Kenya, land rental markets, where they exist, operate without clearly defined regulations to govern lease arrangements. Consequently, transactions in the land rental market are often conducted verbally, resulting in uncertainty about the duration as well as the security of tenure. Because of insecurity of tenure, the households may be forced to operate small parcels of land irrespective of their family 
labour endowments. Nevertheless, the existence of well functioning land rental markets alone does not guarantee that the land-constrained households will rent in land.

Low capital accumulation and credit constraints could be other underlying reasons for the households' reluctance to adjust their scale of operation in order to reduce the implicit cost of family labour. Reliance on one type of marketed output (coffee) makes the households vulnerable to production and price risks, and hence exposes them to liquidity constraints. Moreover, low profit margins can cause farmers to be conservative on their use of capital to the extent that they may be hesitant to expand their scale of operation if the enterprise is deemed less profitable. Nevertheless, the role of credit in breaking the vicious circle of low productivity on smallholder farms cannot be underestimated if lack of access to credit is the main cause of low capital accumulation. Nonetheless, only when low capital accumulation is caused by lack of access to enough land as well as modern land augmenting inputs will access to credit aid in improving productivity and efficiency of use of resources on smallholder farms.

\section{Allocative efficiency}

Allocative efficiency estimates show that the inefficiency due to inappropriate input mix accounts for the loss in income of about $23 \%$, on average, in more than $90 \%$ of the households, indicating the households' failure to respond to price and resource scarcity. Moreover, lack of cost minimising behaviour is found to be severe in the small farm category. The analysis of slack variables suggests that labour input has the highest proportion of households with positive slacks, indicating excessive use of labour, compared with land and variable inputs. In addition, the study reports evidence of the existence of a distinct pattern of input misallocation across the farm categories. While small farms show the tendency to overuse labour and variable inputs, large farms show the tendency to use land extensively. Overuse of labour among the households in general and on small farms in particular can be attributed to the surplus family labour who finds themselves idle during off-peak seasons with little or no farm work to engage in. The results show that the largest proportion of active family labour force remains on the farm because of lack of outside employment, thereby driving the marginal productivity of labour low. This perhaps explains why allocative efficiency is significantly lower on small farms than on large farms.

Besides overuse of labour, the results show that small farms tend to overuse variable inputs relative to medium and large farms. The tendency to overuse variable inputs on small farms reflects an attempt by the small farms to substitute the relatively cheap variable inputs for land. Yet the available land may be too small to utilize the variable inputs fully. Alternatively, overuse of variable inputs can be partly explained by the composition of variable inputs. An in-depth analysis of the composition of variable inputs (Table 1 ) reveals that the opportunity cost of owned seed and manure constitutes a larger share of the total expenditures on variable inputs used by the households. Because the marginal cost of owned inputs, according to the farmers, is zero, there may be a greater tendency for the land-constrained households to overuse owned inputs in an attempt to alleviate land constraints.

Although the study documents cases of overuse of land, especially in the large farm category, the potential saving that the inefficient households would make from land if they operated like the best practice farms is small (an average of $0.04 \mathrm{ha}$ ). Nonetheless, the excessive use of land observed among a few households could be reflective of the poorly functioning land rental markets and credit markets. Lack of well functioning land rental markets may hamper the distribution of land from land abundant households to land constrained households. On the other hand, poorly functioning credit markets may curtail the functioning of land rental markets, thus encouraging unproductive use of land. This is likely to occur if the land-constrained households are also credit- constrained, as observed in this study. It may also be the case that households in the large farm category show the tendency to use land extensively because of credit-constraints.

\section{SUMMARY AND CONCLUSIONS}

This paper has examined the effect of farm size on three components of productive efficiency, namely technical, scale, and allocative efficiency, using an inputoriented data envelopment analysis model. The results suggest that gains from improving technical efficiency exist in all farm categories, although they appear to be much higher on large and on medium farms than on small farms. While small farms tend to use land more intensively in an attempt to alleviate land constraints, the study suggests that the relatively higher level of technical efficiency observed on small farms is mainly attributable to the adoption of traditional land saving techniques rather than the use of modern land saving technologies. Thus, the findings suggest that land scarcity in itself is not sufficient to induce a desired level of technical efficiency. Scale inefficiency is found to account for a larger share of technical inefficiency on small farms than on medium and on large farms, suggesting that increasing the scale of operation is necessary if the households have to reduce implicit labour costs and improve technical efficiency. Likewise, small farms are found to be less allocatively efficient than medium and large farms; nevertheless, gains from improving allocative efficiency exist in more than $90 \%$ of the sample households.

Some of the underlying reasons for the low productive efficiency observed on the smallholder farms include shortage of rental land, as every household tries to eke out a living from land; poorly functioning or missing land rental markets; and lack of working capital due to low capital accumulation and lack of access to credit. Although some of these recommendations may require 
rigorous data to corroborate their applicability, measures aimed at increasing the households' marketed surplus and improving the functioning of land rental markets and credit markets can significantly improve productive efficiency. Well functioning land markets can facilitate the flow of capital from capital -abundant but land-constrained households on the one hand and the distribution of land from land-abundant but capitalconstrained households on the other hand. Moreover, improved access to credit may aid in breaking the vicious circle of low productivity on the farms by enhancing capital accumulation, although crop enterprises will have to compete favourably with other enterprises on the farm for the farmers' scarce capital.

\section{REFERENCES}

Banker, R. D. A. Charnes and W. W. Cooper 1984 Some Models for Estimating Technical and Scale Inefficiencies in Data Envelopment Analysis. Management Science, 30: 1078-1092

Boserup, E. 1965 The conditions of Agricultural Growth. The Economics of Agrarian Change under Population Pressure. New York: Aldine Publishing Company

Binswanger, H., and P. Pingali 1988 Technological Priorities for Farming in Sub-Saharan Africa. Research Observer 3: 81-98

Charnes, A., W. W. Cooper, and E. Rhodes 1978 Measuring the Efficiency of Decision making Units. European Journal of Operational Research, 2: 429-444

Chavas, J. P., P. Ragan, and R. Michael 2005 Farm Household Production Efficiency: Evidence from the Gambia. American Journal of Agricultural Economics, 87: 160-179

Coelli, T. J., D. S. P. Rao and G. E. Battese 1998 An Introduction to Efficiency and Productivity Analysis. Kluwer Academic Publishers, Boston

Cooper, W. W., L. M. Seiford, and J. Zhu 2004 Handbook on Data Envelopment Analysis. Kluwer Academic Publishers, Boston

Färe, R., S. Grosskopf and C. A. K. Lovell 1985 The Measurement of Technical Efficiency of Production.
Kluwer Academic Publishers, Boston

Farrell, M. J. 1957 The Measurement of Productive Efficiency. Journal of Royal Statistical Society, Series CXX, 3: 253-290

Ferrier, G. D., and C. A. K. Lovell 1990 Measuring Cost Efficiency in Banking: Econometric and Linear Programming Evidence. Journal of Econometrics, 46: 229-245

Fried, H. O., C. A. K. Lovell, and S. S. Schmidt 1993 The Measurement of Productive Efficiency: Techniques and Applications. Oxford University Press, New York

Government of Kenya 2003 Statistical Abstract. Central Bureau of Statistics. Ministry of Planning and National Development. Government printer, Nairobi, Kenya

Hayami Y. and W. V. Ruttan. 1985 Agricultural Development: An International Perspective. The Johns Hopkins University Press, Baltimore and London

Helfand, S. M., and E. S. Levine 2004 Farm Size and the Determinants of Productive Efficiency in the Brazilian Center-West. Agricultural Economics, 31: 241-249

Jayne, T. S., T. Yamano, M. Weber, D. Tschirley, R. Benfica, A. Chapoto, and B. Zulu 2003 Smallholder Income and Land Distribution in Africa: Implications for Poverty Reduction Strategies. Food Policy, 28(3): 253-275

Lovell, C. A. K. 1993 Production Frontiers and Productive Efficiency. In "The Measurement of Productive Efficiency: Techniques and Applications", ed. By H. O. Fried, C. A. K. Lovell and S. S. Schmidt, Oxford University Press Inc. New York

Ray, S. C. 2004 Data Envelopment Analysis: Theory and Techniques for Economics and Operation Research. Cambridge University Press, New York

Reardon, T., V. Kelly, T. Jayne, K. Savadogo, and D. Clay 1996 Determinants of Farm productivity in Africa: A Synthesis of Four Case Studies.[Online]. Available: http://www.msu. edu/agecon/fs2/papers.pdf [2005, June 10]

Rios, A. R., and G. E. Shively 2005 Farm Size and Nonparametric Efficiency Measurements for Coffee Farms in Vietnam. [Online]. Available: http://www. purdue.edu/staff/shively/RS [2006, February 10]

Zhu, J. 2002 Quantitative Models for Performance Evaluation and Benchmarking: Data Envelopment Analysis with Spreadsheets and Excel Solver. Kluwer Academic Publishers, Boston 